\title{
O Teatro Esperança no processo das políticas públicas para o patrimônio na cidade de Jaguarão - RS
}

\author{
The Esperança Theatre in the process of public policy for theme of \\ cultural heritage in Jaguarão - RS City \\ El Teatro Esperança em el processo de políticas públicas para el \\ patrimonio en ciudad de Jaguarão - RS
}

\author{
${ }^{1}$ Carlos José de Azevedo Machado; ${ }^{2}$ Vinicius Pacheco Machado; ${ }^{3}$ Ma. Ângela Mara Bento \\ Ribeiro
}

\begin{abstract}
1jmaninho@gmail.com, Universidade Federal de Pelotas; 2 viniciuspacheco96@ hotmail.com, Universidade Federal do Pampa; ${ }^{3}$ angetur.ribeiro8@ gmail.com, Universidade Federal do Pampa.
\end{abstract}

\begin{abstract}
Resumo
Na cidade de Jaguarão (Brasil) encontramos o terceiro mais antigo teatro do Estado do Rio Grande do Sul, o Teatro Esperança, que teve sua linha histórica atravessada por momentos de auge até chegar a um processo de depreciação e desuso. Não obstante, tornou-se um dos principais bens patrimoniais deste município, alimentado pelas políticas públicas para o patrimônio elencadas a partir da década de 1980, chegando, mais recentemente, ao processo de restauração. Nesse contexto, buscamos apresentar a relação deste processo de recuperação lenta e gradual do Teatro Esperança e o momento de aceleração desta recuperação com as políticas públicas apresentadas ao longo das últimas décadas até sua restauração. Para este intento nos utilizamos das análises das Políticas Públicas e do histórico do teatro, suscitadas pelos autores trabalhados e a documentação existente numa sequência de: descrição, análise e interpretação.
\end{abstract}

Palavras-chave: Políticas públicas, memória, patrimônio cultural, Teatro.

\begin{abstract}
In the city of Jaguarão (Brazil) find the third oldest theater of Rio Grande do Sul state, the Esperança Theatre, which had its historical line crossed by the height of times until it reach a depreciation process and disuse and more recently, a process restoration. Nevertheless, it has become one of the main assets of this border city, fueled by public policy for the heritage listed from the decade of 1980. In this context, we seek to present the relationship of this slow and gradual recovery process of the Esperança Theatre and the time acceleration of this recovery with public policies presented over the last decades until its restoration. For this purpose we used the analysis of public policies and theater history, raised by the authors and documentation, in a sequence of: description, analysis and interpretation.
\end{abstract}

Keywords: Public policies, memory, cultural heritage, Theatre. 


\section{Introdução}

Jaguarão, pequena cidade no extremo sul do Brasil conta hoje com 28 mil habitantes, mas que somados aos da cidade gêmea de Rio Branco (Uruguai), alcança 45 mil pessoas, que habitam um mesmo local geográfico: $O$ entorno do Rio Jaguarão, em meio a uma linha imaginária que chamamos de Fronteira. Nela encontra-se um vasto patrimônio arquitetônico edificado e uma riqueza cultural e natural bem preservada e é onde se encontra o Teatro Esperança, terceiro mais antigo do estado brasileiro do Rio Grande do Sul, precedido apenas pelo Teatro Sete de Abril de Pelotas e o Teatro São Pedro em Porto Alegre. Este teatro passou por vários momentos, do apogeu até sua decadência, ficando com suas portas fechadas nas últimas décadas do século XX. Mas, recentemente o teatro passou por um processo de restauração que se concluiu em 13 de novembro de 2015, quando foi devolvido à comunidade. Para chegar até este momento, houve um caminho lento e gradual de ações políticas que começam a se constituírem a partir do início dos anos de 1980. Para abordar este processo, começaremos apresentando o Teatro Esperança, para depois abordarmos de forma geral as políticas públicas para o patrimônio e por fim, voltarmos ao teatro e a atual situação.

\section{A arte teatral em Jaguarão}

A arte teatral em Jaguarão, de forma geral, começa logo em seguida de sua elevação a vila (metade do século XIX) já com o funcionamento de pelo menos dois teatros, que não existem mais. Isto por conta de sua localização geográfica privilegiada, com ligação direta com Pelotas e Rio Grande através do Canal de São Gonçalo, bem como com o Uruguai. Estes fatores vão fazer com que a então Vila de Jaguarão receba estes elementos artísticos e dramáticos.

Devido a esta proximidade com Montevidéu (Uruguai) e Pelotas e Rio Grande pelo Brasil, chegavam à cidade muitas companhias de espetáculos que vinham pelas águas da Lagoa Mirim e Canal de São Gonçalo. Aproveitavam esta rota e excursionavam pelo sul, transitando da capital da Província, passando pelo Uruguai, chegando à Argentina (MARTINS, 2001, p. 250). Outro pesquisador, Lothar Hessel, chama atenção para o fato de que também havia o movimento contrário, do Uruguai para o Brasil: muitas companhias europeias que vinham para o Brasil, passando por Montevidéu, de lá entravam em nosso país por Jaguarão, onde ficavam de um a três meses para acertar o visto de entrada. Por conta disto a cidade se mobilizou para a construção de um grande Teatro à altura destas companhias. (HESSEL, 1999, p. 78). A construção desta obra também serviu para ostentar a riqueza 
oriunda das últimas três décadas, em função do charque e contrabando. Ainda segundo Hessel (1999, p. 80) há três aspectos que se relacionam com o teatro em Jaguarão: "a imprensa local fazendo a crítica sobre os espetáculos; as visitas de companhias espanholas ou platinas que subiam de Montevidéu, [...] e a visita de grandes companhias circenses que em seus picadeiros apresentavam teatro popular de arena".

\subsection{O Teatro Esperança}

O Teatro Esperança começou a ser construído ainda no período monárquico, em 1887, e inaugurado onze anos depois, já no período republicano, em 1898, sob os domínios do Partido Republicano e de suas lideranças na cidade, como Carlos Barbosa Gonçalves e Zeferino Lopes de Moura (FRANCO, 2001). Segundo Cleó dos Santos Severino “o Teatro Esperança é possuidor de uma acústica perfeita, permitindo que se escute de qualquer ângulo de sua grande sala os mínimos sons produzidos" (Jornal CORREIO DO POVO, 1983). Não é incomum ouvir relatos de que foi uma das melhores acústicas do Brasil, porém não encontramos nenhuma prova ou análise técnica que corroborasse a afirmação. Este teatro começou a ser construído em 1887, através de uma sociedade anônima, com a denominação inicial de "Teatro 27 de Janeiro", mas concluído onze anos depois com uma nova denominação, agora Teatro Politeama Esperança. Inaugurado em 13 de janeiro de 1898 foi considerado o primeiro do estado por muitos anos, devido às suas excelentes condições, em especial a qualidade acústica.

O primeiro ano de gestão foi bastante intenso em atividades chegando a 103 espetáculos conforme o Relatório da Associação do Teatro Polyteama Esperança, apresentado na assembleia do dia 21 de janeiro de 1899. Ao longo de sua história o controle do teatro se deu através de três Associações e uma Sociedade Comercial, até ser municipalizado em 1997. A primeira constituída em 1886 dá inicio a obra, mas não consegue verba para concluí-la e vai a leilão, quando assume o controle do teatro uma nova associação concluindo a obra. $\mathrm{O}$ estatuto desta Associação previa sua duração por 30 anos, o que em 1929, através de uma assembleia, foi constituída a terceira associação, com o capital social da antiga além de novos sócios, perdurando até 1959. Porém, já em 1957 a SOJAL (Sociedade Imobiliária e Comercial de Jaguarão) assumiu o controle acionário da Associação Teatro Esperança S.A. Na primeira década do século XX com a chegada do cinema, uma invenção que acabou abalando as funções teatrais que até então tinha hegemonia no entretenimento, será o principal fator que irá manter o teatro aberto constantemente até o final da década de 1950. A SOJAL, última 
proprietária antes da municipalização, também construiu o Cine Regente no final da década de 1950 e acaba com as projeções no Esperança. Além do fechamento da parte cinematográfica no teatro, significou também o fechamento do mesmo. A partir da década de 1960 o teatro permanece a maior parte do tempo com suas portas fechadas, abrindo esporadicamente para atividades escolares e eventuais espetáculos que vinham à cidade, além de atividades cívicas e políticas, situação que perdurou até meados do início do século XXI.

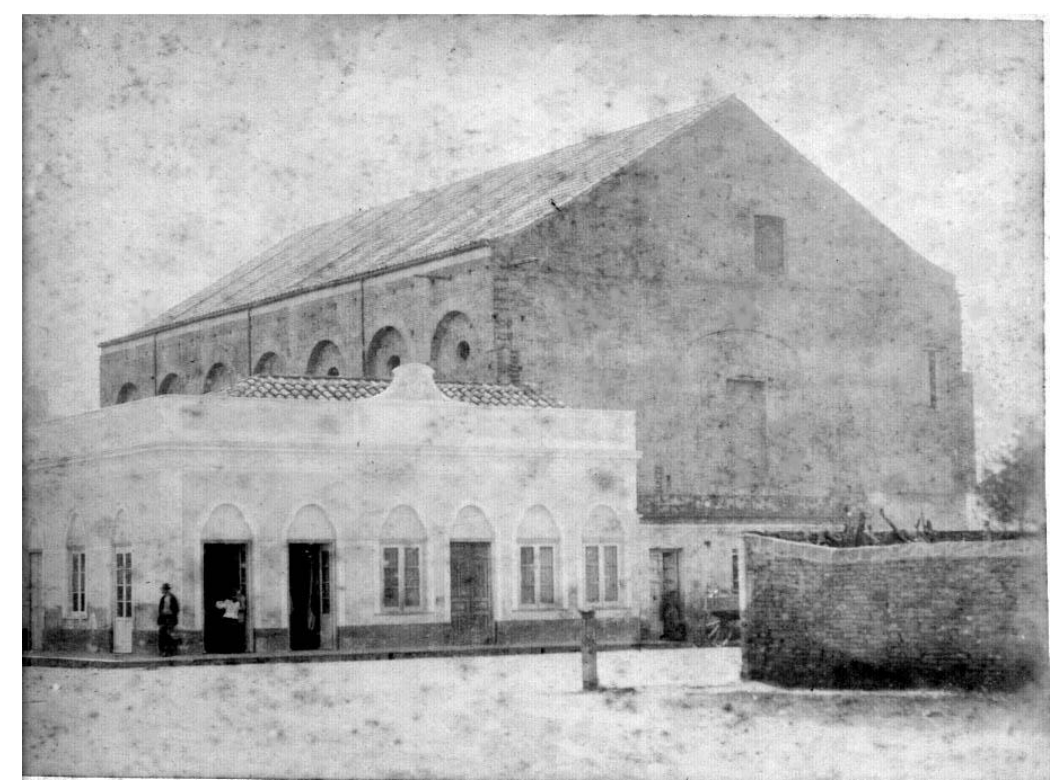

Figura 1 - Plano geral da frontaria principal / sem datação. Possivelmente por volta de 1897. Acervo do IHGJ $^{1}$

Sua arquitetura foi projetada em estilo eclético, "em cuja fachada fora colocada aberturas entre as colunas jônicas e as platibandas com frontões decorados" (MARTINS, 2001, p.249-250) que revelam a precisão dos grandes artífices do continente europeu, que percorreram e se instalaram no sul do país, em meados do século XIX. Seu construtor, Martinho de Oliveira Braga, se destacou pela atuação em diversas obras que compõem o requintado casario do município, e o responsável pelo trabalho em madeira foi o artista Gustavo Guimarães, marceneiro português estabelecido na fronteira à época. A pintura do teto interno, um dos pontos altos da obra, é de autoria de Baltazar Gonçalves Ramos, pintor radicado no município neste período, mas pouco se sabe sobre ele. A caixa cênica segue o estilo italiano e a parte central eleva-se em quatro níveis. No pavimento térreo, a plateia tinha a capacidade para abrigar até quatrocentas pessoas sentadas, tendo funcionado também como

\footnotetext{
${ }^{1}$ Instituto Histórico e Geográfico de Jaguarão
} 
picadeiro, onde as cadeiras eram removidas e o piso da plateia cedia lugar ao "chão batido" (o tablado era móvel) próprio às apresentações circenses (PATRIMONIUM, 2010).

A seguir duas fotos, uma antiga e outra mais recente durante a reinauguração em 13 de novembro de 2015, mostram o teatro com destaque para as galerias onde, na primeira observamos os camarotes originalmente subdivididos e individualizados, o que foi modificado na década de 1950 e mantido assim na atualidade, em função das novas funcionalidades e usos pela comunidade.
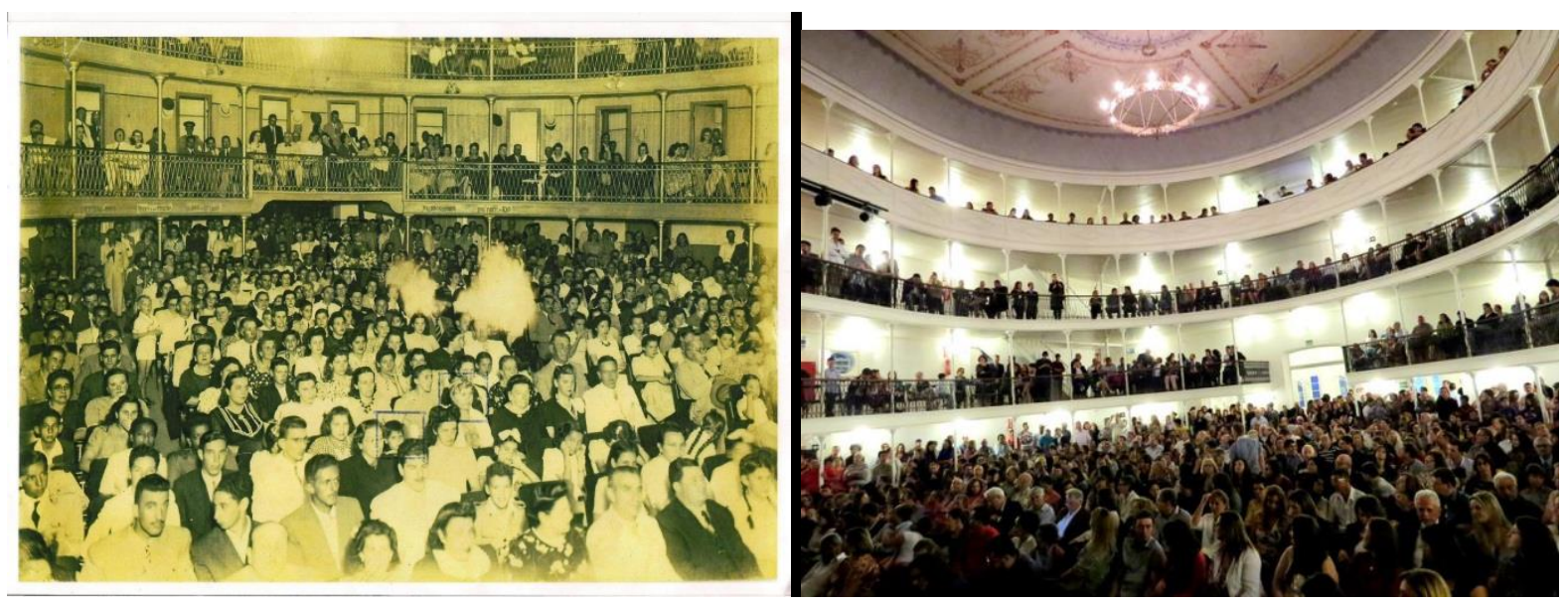

Figura 2 _ Foto 01 (antiga): Vista da plateia com os camarotes ao fundo / sem datação (fonte IHGJ) Foto 02: Na reinauguração em 13/11/2015. Fonte: Arquivo de Roberto Luzardo

Em matéria no Jornal "A Folha", de 13 de maio de 1991, a pesquisadora Maria Dutra da Silveira apontava três fases na história deste teatro que bem o caracterizam: Construção e primeiros passos (período da ascensão); funcionamento nas primeiras décadas do século XX (apogeu) e decadência com a absorção pela companhia que construiu o cinema. (JORNAL A FOLHA, 20/05/1991, p.4). Silveira também alertou de que a história ainda estava sendo escrita, quando um ano antes, em 1990, tinha acontecido o tombamento estadual, e havia os rumores de que o teatro poderia ser municipalizado, que acabou acontecendo em 1997 e em 2015, já podemos incluir mais uma fase em sua história: a restauração.

\section{As políticas públicas para o patrimônio na cidade de Jaguarão}

As primeiras discussões em relação às políticas públicas para o patrimônio remetem ao início dos anos de 1980, conturbado período político-econômico, últimos anos da ditadura militar. Não se pode dizer o mesmo com relação ao debate das políticas patrimoniais, pois o Brasil sofre a influência dos debates sobre o Patrimônio oriundos da Europa, especialmente a Convenção da ONU em 1972 - para proteção do patrimônio mundial, cultural e natural - e do 
ano europeu do patrimônio em 1975. Nele pretendeu-se ir muito além da ideia tradicional de patrimônio, conforme nos apresenta Leonardo Castriota (2010, p. 94):

\begin{abstract}
Organizada pelo Conselho da Europa, com o objetivo de 'outorgar à conservação do patrimônio histórico, cultural e imobiliário da Europa o lugar que lhe corresponde no contexto do planejamento urbano e territorial', aquela iniciativa vai ter, na verdade, a intenção - mais ampla - de conseguir 'a definição de uma política europeia de ordenação do território'.
\end{abstract}

De acordo com Maria Cecília Londres Fonseca, "a constituição de patrimônios históricos e artísticos nacionais é uma prática característica dos Estados modernos" (1997, p. 21) e o discurso que costuma justificar a constituição desses patrimônios bem como o desenvolvimento de políticas públicas de preservação, busca valorar estes enquanto manifestações culturais e enquanto símbolos da nação. Assim, as políticas de preservação "se propõem atuar basicamente no nível simbólico, tendo como objetivo reforçar uma identidade coletiva, a educação e a formação de cidadãos". (Ibid., p. 21)

Dentro do contexto nacional na década de 1970, os debates fomentados na sociedade civil em Jaguarão gestaram projetos que resultaram no levantamento arquitetônico dos prédios da cidade, na forma de inventário, com vistas à preservação do patrimônio seguindo a linha apresentada por Fonseca, buscando valorar os lugares apresentados como símbolos patrimoniais da cidade. O projeto considerado "pioneiro", desenvolvido no começo dos anos 80, denominado Jaguar ${ }^{2}$, englobou diversas ações além do inventário, com a utilização de espaços culturais como o Teatro Esperança e a valorização das ruínas da Enfermaria Militar. $\mathrm{Na}$ "Ficha Técnica da Proposição - Estudo Preliminar" do Projeto Jaguar, entre os objetivos estava "estabelecer a memória comunitária" e apresentava na alínea "a": "ativar o Theatro Esperança, primeiro teatro politeama do estado, com apresentações periódicas de espetáculos" (NUNES; GARCIA, 1983).

Em setembro de 1983, a Prefeitura Municipal e a Universidade Federal de Pelotas (UFPel) firmaram um convênio, com a finalidade de desenvolvimento de um programa de cooperação técnico-cultural-científica e de extensão, na cidade de Jaguarão, através de projetos específicos e que foi novamente acordado em 1987.

\footnotetext{
2 Sobre este movimento, o registro a seguir consegue retratar bem o momento inicial: “A primeira ação referente à preservação do patrimônio cultural de Jaguarão, mapeada neste trabalho, é o Projeto Jaguar, de 1982. A ideia surgiu quando dois moradores de Jaguarão, Jorge Garcia e Valdo Nunes, estudavam arquitetura na Faculdade Ritter dos Reis, em Porto Alegre. Durante as discussões na disciplina de arquitetura Brasileira, ministrada na época pelo professor Nestor Torelli Martins, os dois alunos perceberam que Jaguarão tinha uma arquitetura representativa" (ZORZI, 2012, p. 62. IN: BÔAS; COSTA, Cadernos Jaguarenses, Vol.5, 2013).
} 
[...] Com base em tais premissas, a pró-reitora de Extensão através da Faculdade de Arquitetura e Urbanismo da Universidade resolveu instituir programa, objetivando a recuperação das ruínas da enfermaria militar, a começar pelo levantamento físico, histórico e fotográfico, seguido da limpeza do terreno, implantação de placa de identificação do projeto, análise e diagnóstico e estudo de viabilidade (JONAL DA UFPEL, 1987, p 15).

Desta forma, os primeiros registros de uma preocupação com o patrimônio histórico e arquitetônico da cidade se dão neste período e contaram com mobilizações e movimentos da sociedade civil que chamavam a atenção para a necessidade de revitalização de nossos prédios, espaços públicos e locais de interesse cultural. A proposta de revitalização de Jaguarão surge através de ações não governamentais como o Projeto Jaguar, no ano de 1982, e irá influenciar muitas pessoas e entidades da comunidade. Após a primeira eleição depois da Ditadura (1985), o prefeito eleito, Fernando Correa Ribas, entusiasmado com a movimentação deste projeto, institucionaliza algumas atividades e começa a organizar a revitalização das Ruínas da Enfermaria, acarretando a criação de um parque no local. Com a morte deste prefeito em um acidente automobilístico, o parque acabou levando seu nome. Porém na década de 1990 as novas gestões acabam gerando um novo e forte abandono deste espaço.

Contudo, importantes frutos do Projeto Jaguar germinaram: em 1987 é celebrado um novo convênio entre Prefeitura e UFPel, que leva ao posterior surgimento do PRIJ -Programa de Revitalização Integrada de Jaguarão, que gerou um livro com o mesmo nome, publicado em 2005. Ainda como consequência desta movimentação surge em 1987 a SIC - Sociedade Independente Cultural, com forte influência do Projeto Jaguar e que vai protagonizar algumas atividades importantes na área cultural, em especial o Projeto Jaguararte $^{3}$ no Teatro Esperança. Em 1990 a cidade teve 04 prédios tombados pelo Instituto do Patrimônio Histórico e Artístico do Estado do Rio Grande do Sul (IPHAE): Teatro Esperança, Ruínas da Enfermaria Militar, Mercado Público e Casa de Cultura. Em 2005 iniciou a promoção de um encontro anual sobre arquitetura, turismo cultural e preservação, o Seminário de Arquitetura de Jaguarão promovido pelo SEBRAE em parceria com a Prefeitura Municipal, que culminou com a publicação, em 2009 da obra Roteiros de Arquitetura da Costa Doce. Outro fator importante foi com a fundação da Universidade Federal do Pampa, em 2006, onde Jaguarão é contemplada com um Campus desta instituição, o que irá potencializar a cidade e região do ponto de vista cultural.

Um pouco antes, em 2001, o Estatuto da Cidade (Lei Federal 10.257) consagra as cidades sustentáveis, buscando assegurar às presentes e futuras gerações condições dignas de

\footnotetext{
${ }^{3}$ Projeto realizado no Teatro Esperança que visava difundir a produção cultural local. Aconteceram em 1992 e 1993, retomado em 2005 e se estendeu até 2009, quando começou o processo de restauro do Teatro.
} 
vida, de participação na gestão da cidade e de viver em cidades com qualidade de vida. Para se utilizarem deste Estatuto, os municípios com mais de 20 mil habitantes precisavam ter um Plano Diretor, com participação da comunidade na hora de fazer, votar e colocar o Plano Diretor em prática.

Desta forma, o Poder Executivo Municipal juntamente com o Poder Legislativo, se empenham na elaboração deste Plano. Realizou-se o I Encontro de Capacitação do Plano Diretor Participativo de Jaguarão, no dia 28 de junho de 2006. Após aconteceu um calendário de reuniões entre o Comitê Gestor com lideranças comunitárias e entidades, levando à elaboração do atual Plano Diretor. Entre as leis que fazem parte do Plano Diretor Participativo de Jaguarão (PDPJ), elencamos aqui a Lei $\mathrm{N}^{\circ} 4.682 / 07$, que institui a Preservação do Patrimônio Histórico Arquitetônico e Turístico de Jaguarão (PPHT) e a Lei no 4.685/07 que institui o Código de Obras do Município e integram o novo Plano Diretor (LEI COMPLEMENTAR 07/2006). Ambas tratam de perto esta questão do patrimônio, já levando em conta o Inventário realizado pela UFPel (PRIJ). Além destas leis, há outras que também dialogam com o tema, e que podem ser acessadas pelo site da prefeitura municipal ${ }^{4}$.

Com a mudança da Gestão municipal em 2009, a Secretaria de Cultura e Turismo (SECULT) é desmembrada do Desenvolvimento Econômico, e o grupo que assumiu esta pasta tinha influência direta do Projeto Jaguar e da SIC. Neste momento os passos se dão de forma mais acelerada para a consolidação de políticas públicas do Patrimônio Cultural, dando sequência a uma nova fase deste processo que vinha caminhando de forma positiva, porém ainda lentamente. A gestão buscou um diálogo mais direto com o Instituto do Patrimônio Histórico e Artístico Nacional (IPHAN) e em abril de 2009 organizou o Fórum de Patrimônio Histórico e Cultural de Jaguarão, em parceria com o IPHAN, o que desencadeou uma série de ações nesta área.

A restauração concluída em 2015 do Teatro Esperança ocorreu neste período, tendo começado sua execução em janeiro de 2010. Em 2011 acontece o tombamento nacional do Centro Histórico de Jaguarão ${ }^{5}$, em 2012 o tombamento Binacional da Ponte Internacional Mauá e em 2013, onze projetos foram aprovados pelo Programa de Aceleração do Crescimento (PAC-Cidades Históricas), que totalizarão 40 milhões de reais. Neste rol, está incluída a terceira fase do Teatro Esperança. Também aconteceram neste período debates com grupos ligados à religiosidade e cultura afro-brasileira o que levou ao surgimento de

\footnotetext{
${ }^{4}$ http://www.jaguarao.rs.gov.br/?page_id=316

5 As informações e dados sobre o tombamento se encontram no "Dossiê de Tombamento do Conjunto Arquitetônico e Paisagístico de Jaguarão” editado pelo Ministério da Cultura/IPHAN em 2010.
} 
atividades relacionadas ao Patrimônio Imaterial com as festas de Iemanjá e São Jorge, que eram tradicionais, mas pareciam invisíveis para muitos jaguarenses bem como para as políticas públicas locais, além de outras atividades como o artesanato local e demais festas religiosas e folclóricas.

\subsection{O Teatro neste processo de políticas públicas}

O Teatro Esperança começa a ser pensado como um Patrimônio a ser revitalizado e restaurado com o Projeto Jaguar. A sua situação de quase abandono, levou a uma matéria no jornal Correio do Povo no início dos anos de 1980 com o seguinte título: "Jaguarão perde aos poucos, seu Teatro Esperança. A Crescente deterioração do prédio, um dos mais bonitos do País, abre novo vazio na atividade cultural do Rio Grande do Sul" (JORNAL CORREIO DO POVO, 24-04-1983, p. 44).

Nesta matéria é abordada a precária situação do prédio e apresentado um histórico do mesmo, baseado no pesquisador jaguarense Cléo dos Santos Severino; também são expostas as visões da proprietária à época, SOJAL, e a visão da Prefeitura. Esta discussão levantada num jornal de circulação estadual deu-se possivelmente por conta da movimentação e dos ecos do Projeto Jaguar. Outra matéria, também em jornal estadual, sobre a Vigília que aconteceu nas ruínas da Enfermaria, em 1984, saiu no Jornal "Folha da Tarde" e teve como chamamento: "Um dia de vigília em busca da preservação, em Jaguarão" (JORNAL FOLHA DA TARDE, 28-02-1984, p.30).

Em 12 de junho de 1990, o Teatro foi tombado pelo IPHAE/RS (Instituto do Patrimônio Histórico e Artístico do Estado do Rio Grande do Sul), e em 1997 municipalizado, porém a desapropriação oficial se deu em 22/08/2001. Este processo aconteceu através de articulação com o IPHAE/RS e da participação da sociedade através de consultas a várias entidades, entre elas a Sociedade Cultural Joaquim Caetano da Silva, a Sociedade Independente Cultural, o Instituto Histórico e Geográfico de Jaguarão. No entanto, mesmo após a municipalização, seu uso não avançou muito, tendo utilizações esparsas pela comunidade.

Em 16/04/1998 foi aprovado Projeto de Recuperação da Cobertura pela Secretaria de Estado da Cultura (SEDAC-RS), tendo como Produtora Cultural a Sociedade Cultual Joaquim Caetano da Silva e patrocinador a Companhia Extremo Sul. Porém em fevereiro de 1999 aconteceu um embargo da Obra de Recuperação, apresentado pelo Ministério Público, justificando que não estava sendo executada conforme estabelecido pelo IPHAE. Em maio de 
2004 é assinado um Termo de Acordo de Conduta (TAC) entre Prefeitura, Governo do Estado e Ministério Público para tentar resolver o problema. Ao final, este processo de restauro fracassado acabou prejudicando a harmonia do conjunto, apesar da boa vontade de muitos em buscar a melhoria do teatro. Faltou aí a falta de um grupo técnico mais especializado no município e um acompanhamento mais direto dos órgãos estaduais, já que se tratava de um bem tombando pelo estado, à época.

Em 2005 o arquiteto William Pavão Xavier, como Produtor Cultural, apresenta o Projeto de restauro, em caráter emergencial, da cobertura e palco do Teatro Esperança, para colocar na Lei de incentivo a cultura da época (LIC/RS). Em 2008 o projeto também estava cadastrado na Lei Rouanet (Federal). Coube ao município, em 2009, ouvido a Secretaria de Cultura e Turismo, contratar o Projeto da Empresa Patrimonium Arquitetura, liderada pelo arquiteto Pavão, que permitiu a execução da primeira fase do restauro, com verba direta do Iphan, através da articulação mais direta da Prefeitura Municipal junto àquele Instituto. Esta fase começou em janeiro de 2010, a cargo da empresa Marsou Engenharia, vencedora da licitação, e restaurou a cobertura, buscando a vedação do prédio, além da restauração da pintura do teto interno.

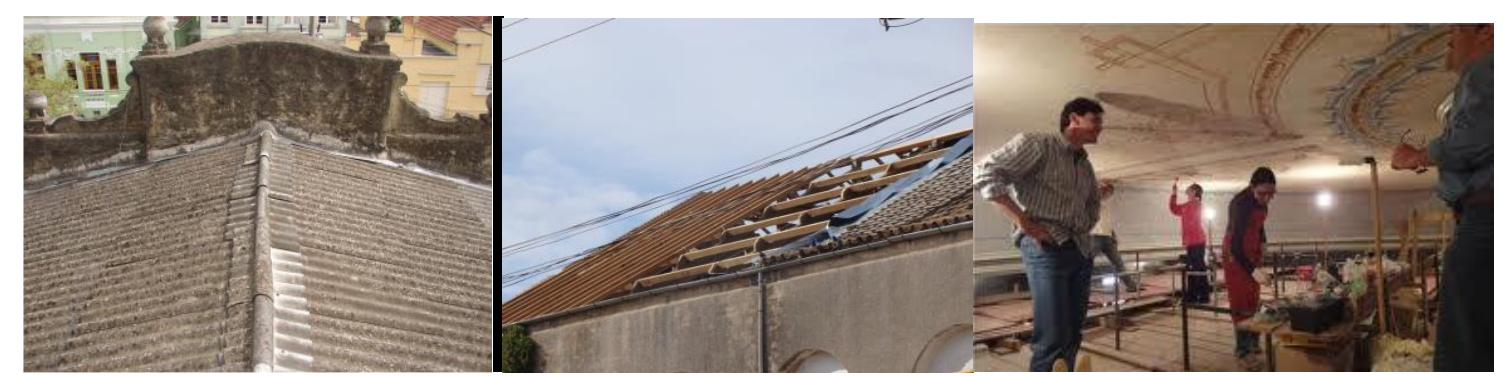

Figura 3 _ Foto 01: telhado antes do restauro. Foto 02: durante o restauro. Foto 03: Restauro do teto interno. Fotos do acervo da SECULT

Em 03 de maio de 2011 foi anunciado pelo IPHAN o tombamento do conjunto histórico e paisagístico do centro urbano da cidade de Jaguarão e neste mesmo ano começa a $2^{\mathrm{a}}$ fase do restauro, com os estudos arqueológicos e posteriormente a execução da parte interna e externa. A pesquisa arqueológica foi possibilitada por um convênio entre o município e a reitoria da UNIPAMPA, sendo a execução da segunda fase, a cargo da mesma empresa anterior, e compreendeu a recuperação do palco, camarins, plateia, balcão nobre, escadas, foyer, piso, forro, lustre, urdimento, construção de banheiros, luminotécnica e sonorização. A previsão inicial para conclusão da obra era para o final de 2014, porém foi inaugurado em 13 de novembro de 2015. O motivo do atraso, exposto pela SECULT foi os 
ajustes do Projeto quanto ao Plano de prevenção e proteção contra incêndio (PPCI), o que necessitou de uma nova verba para as adequações e novas intervenções.

No PAC - Cidades históricas (Plano de Aceleração do Crescimento para cidades históricas) do Governo Federal, a terceira fase do restauro do Teatro Esperança está incluída dentro dos projetos aprovados. Esta intervenção se dará no prédio que fica atrás do teatro e que faz parte do conjunto, ${ }^{6}$ sendo que será executada posteriormente, independentemente dos usos do Teatro Esperança, uma vez que fica anexo a este.

\section{Considerações finais}

O Teatro Esperança, um bem patrimonial cultural, materialmente edificado e que possibilita uma série de memórias na comunidade que com ele interage, mesmo considerando suas portas fechadas por cerca de 50 anos, manteve-se numa condição de símbolo do Patrimônio Cultural da cidade, testemunhado em pesquisas já realizadas como pelo Projeto Pibid/História/Unipampa/20117, bem como quando foi elencado um dos bens a serem trabalhados pelo Projeto Jaguar. Ora, Llorenç Prats (2005) considera Patrimônio primeiramente uma construção social, dialogando com a ideia da prática de memória obedecendo a um projeto de afirmação de si mesma em Joel Candau (2011). Pois para que determinados elementos se constituam como patrimônio têm de ser resgatados de um corpus cultural mais ou menos difuso e sujeitos a uma engenharia social que lhes confere valor e significado.

Este trabalho nos permitiu perceber que este teatro adquiriu um significado que lhe permitiu este status quo pela comunidade, sendo fruto direto das políticas públicas para o patrimônio que se desenvolveram nas décadas de 1980 até a atual. Das discussões do Projeto Jaguar, do tombamento estadual, da municipalização, da tentativa de restauração na virada do último século até a contratação do atual projeto de restauração e sua execução, todos estes passos estão relacionados à macro política, mas que por si só não se constituiriam se não fosse por conta de seu significado para a comunidade.

Dentro da dinâmica que vem se efetivando desde 2009, nesta relação direta com o Iphan, o Teatro Esperança foi o primeiro bem patrimonial que sofreu um processo de

\footnotetext{
${ }^{6}$ No final do século XIX este espaço era muito usado para a passagem de animais, pois o teatro servia também para leilões e apresentações circenses, onde as cadeiras eram removíveis. Também ficava um depósito de carbureto, combustível de iluminação e uma cocheira, situada junto da frontaria de fundos do teatro. (PAVÃO, 2010, p.3)

${ }^{7}$ Pesquisa realizada pelo Programa Institucional de Bolsas de Iniciação à Docência, PIBID História/Educação Patrimonial Unipampa, edital CAPES 2011, com publicação da Cartilha “Compartilhando os bens de Jaguarão".
} 
restauração e também foi o primeiro a ser entregue à comunidade. Resta agora o cuidado com os próximos passos. O Teatro Esperança, agora entregue a cidade restaurado e revitalizado, não será por si só garantia de que o mesmo manter-se-á sempre ativo junto à cidade. A garantia de sua continuidade ativa passará pelo debate da gestão e uso deste bem. O envolvimento organizado da comunidade torna-se importante para que estas políticas deem certo. Como nos coloca Prats (2005), ele chama atenção para pensarmos a gestão patrimonial em conjunto (diretrizes), quesito onde se encontra a ideia de continuidade de uso e/ou preservação do bem tombado.

Por fim, importante também, a relação que se possa manter entre o gestor do teatro com a UNIPAMPA, onde, por exemplo, o curso de Produção e Política Cultural pode contribuir na busca de projetos que possam viabilizar e manter o Teatro Esperança sempre aberto, mantendo este vínculo de pertencimento da comunidade com este espaço, reforçando a importância de uma gestão pró - ativa e integrada com o patrimônio cultural da região do entorno do Rio Jaguarão.

\section{Referências}

CANDAU, Joel. Memória e Identidade. São Paulo, Contexto, 2011.

CASTRIOTA, Leonardo Barci. PAC Cidades Históricas - oportunidade para a conservação integrada? In: Locus - Revista de história de Juiz de Fora, v.16, n.2, pp.93-117, 2010.

CODEC/RS, Portaria 06/1990, 05/07/1990. Processo de tombamento $\mathrm{n}^{\circ}$ 00.786-0804 CODEC-1990.6. Inscrição no Livro do Tombo Histórico - fls. - 45. Portaria 06/90 publicada no DOE em 19/07/1990.

FONSECA, Maria Cecília Londres. O patrimônio em processo: trajetória da política federal de preservação no Brasil. Rio de Janeiro: UFRJ/IPHAN, 1997.

FRANCO, Sérgio da Costa. Origens de Jaguarão: 1790-1833. 2 $2^{\mathrm{a}}$ Edição - Porto Alegre: Editora Evangraf Ltda, 2007.

HESSEL, Lothar. Teatro no Rio Grande do Sul. Porto Alegre: Ed. da Universidade/UFRGS, 1999.

INSTITUTO DO PATRIMÔNIO HISTÓRICO E NACIONAL (IPHAN). Dossiê de Tombamento do Conjunto Arquitetônico e Paisagístico de Jaguarão. Porto Alegre: Ministério da Cultura; IPHAN, 2010.

JORNAL A FOLHA, edição de 20/05/1991, artigo de Maria Dutra da Silveira.

JORNAL CORREIO DO POVO, edição de 24/04/1983. 
JORNAL DA UFPEL, Pelotas, março, 1987, Projeto Jaguar.

JORNAL FOLHA DA TARDE, edição de 28/02/1984.

LEI COMPLEMENTAR MUNICIPAL Nº7, instituí o Plano Diretor Participativo de Jaguarão. De 28 de novembro de 2006.

LEI FEDERAL N 10.257/01. Estatuto da Cidade.

MARTINS, Roberto Duarte. A ocupação do espaço na fronteira Brasil - Uruguai: a construção da cidade de Jaguarão. Tese. (Doutorado em Histórias Especializadas) Universidade Politécnica da Catalunha, 2002.

NUNES, Valdo Dutra; GARCIA, Jorge Arismendi. Ficha técnica da proposição - Estudo preliminar. Jaguarão/Prefeitura Municipal, 1983.

OLIVEIRA, Ana Lucia Costa \& SEIBT, Maurício Borges. Programa de Revitalização Integrada de Jaguarão. Pelotas: Editora Universitária UFPel, 2005.

PATRIMONIUM Arquitetura Histórica e Contemporânea. Detalhamento do Projeto de Restauro do Teatro Esperança. $1^{\text {a }}$ Etapa. Jaguarão, 2010. de 2011 .

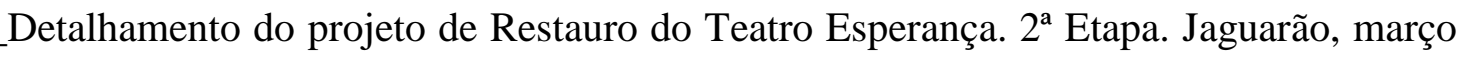

PRATS, Llorenç. Concepto y gestión del patrimonio local. Cuadernos de Antropología Social $\mathrm{N}^{\mathrm{o}} 21$, pp. 17-35, 2005. PDF.

Relatório da Associação do Theatro Polytheama Esperança. Ano de 1898. Typografia da Livraria Commercial, 1898, 1899.

SOJAL. Contrato por instrumento particular de Sociedade por quotas de responsabilidade limitada. 01/04/1957.

ZORZI, 2012. In: BÔAS; COSTA, Cadernos Jaguarenses, Vol. 5, 2013. 